\title{
Resilience thinking and urban metabolism in spatial planning: which possible integrations
}

Marcello Magoni*

\begin{abstract}
The concept of resilience has been used for more than a decade in ever-widening intervention fields and it has assumed ever-wider meanings that have made its applications and measurements uncertain and ambiguous. That is why some authors started to talk about "resilience thinking", to be considered more as a useful idea to draw guidelines and strategies than a rigorous concept.The use of resilience thinking in spatial and urban planning is rather recent and uncommon, while the use of the concept of urban metabolism is much widespread because it is well combined with all those plans that manage resource flows. The integrated use of these two concepts can give an important contribution to the development and implementation of sustainable development strategies. In fact, through the concept of urban metabolism, in which concepts and tools are mostly geared to the integrated and sustainable management of the resources affecting a territorial system, it is possible to define the objectives and intervention strategies for sustainable spatial development, while through resilience thinking, in which concepts and tools are mostly oriented to the management of complex systems under uncertainty and to the elaboration of bottom-up solutions, it is possible to integrate those strategies with suitable solutions in order to enhance the system's adaptation capabilities to risk situations and those of uncertainty.The paper deals with the use of resilience thinking in spatial planning, with the integration between resilience thinking and urban metabolism and gives details of the features of this integration by analysing a strategic spatial project of a river.
\end{abstract}

Keywords: Resilience thinking, Urban metabolism, Spatial planning, Sustainable development

\section{Background}

The concept of resilience has been used for more than a decade in ever-widening intervention fields, including the development of strategies and actions aimed at enhancing the capacity of cities to respond to the ongoing internal and external stresses to which they are subjected, from local to global ones. At the same time, the concept of resilience has assumed ever-wider meanings that, on the one hand, have led it to become an "all-encompassing" concept and therefore useful in building reasoning, on the other hand, have made its applications and measurements uncertain and ambiguous. That is why some authors started to talk about "resilience thinking", considered more as a useful idea to

*Correspondence: marcello.magoni@polimi.it

Dipartimento di Architettura e Studi Urbani (Politecnico di Milano), Via Bonardi 3, 20133 Milan, MI, Italy draw guidelines and strategies than a rigorous concept from which to derive consistent elaborations and applications. The use of resilience thinking in spatial and urban planning is rather recent and uncommon, although there are numerous approaches, aimed at capacity building, enhancing participatory processes, reducing territorial and social vulnerability, and increasing capacity for adaptation which can be also considered to belong to that way of thinking.

In spatial planning and, above all, in the sector one related to territorial infrastructures, the use of approaches that may be related to the concept of urban metabolism is much widespread. This concept was introduced in the spatial planning much earlier, in the early 1970s with the UNESCO Man and Biosphere program, ${ }^{1}$

\footnotetext{
${ }^{1}$ See the website: http://www.unesco.org/new/en/natural-sciences/environment/ecological-sciences/man-and-biosphere-programme/.
} 
and it is well combined with all those plans that manage resource flows, such as plans for the increase of energy and water efficiency, for the reduction of hydro-geological risk, for the protection of air quality, for the reduction of soil consumption and the enhancement of ecosystem services, for the development of sustainable mobility.

The integrated use of these two concepts in spatial planning can give an important contribution to the development and implementation of sustainable development strategies. This integration, favoured by the fact that both concepts adopt a systemic view, would improve the quality and the capacity of the strategies. In fact, through the concept of urban metabolism, it is possible to define the objectives and the intervention strategies for sustainable territorial development in a strict manner, while through resilience thinking it is possible to integrate those strategies with suitable solutions in order to enhance the system's adaptation capabilities to real and potential risk situations and those of uncertainty.

The paper is developed in three parts: the first two are theoretical, while the third exemplifies some of the notions included in the article. The first part deals with the use of resilience thinking in spatial planning, while in the second part the integration between resilience thinking and urban metabolism is highlighted. The third part gives details of the features of this possible integration by analysing a strategic territorial project of river process management and environmental redevelopment. Specifically, there are indicated the project choices that are consistent or not to the application factors that characterize the two concepts considered in this paper.

\section{Resilience thinking and spatial planning}

In resilience thinking, the object of study and intervention that is closer to that of the competence of spatial planning is constituted by the socio-ecosystem, which indicates "a bio-geo-physical unit and its associated social actors and institutions (that is) complex and adaptive and delimited by spatial or functional boundaries surrounding particular ecosystems and their problem context" (Glaser et al. 2008).

Resilience in a socio-ecosystem is given by the "ability (...) to change, adapt, and, crucially, transform in response to stresses and strains" (Carpenter et al. 2005). This skill is exalted in the evolutionary approach outlined in Holling's "adaptive loop" metaphor (Gotts 2007). The resilience is a constantly evolving process that occurs when the system compares with a real or potential disturbance factor, here understood as both a sudden event that has a traumatic effect on the system and a gradual or cumulative event whose effects are incremental and/ or with slight rips. Above all, this comparison must aim at transforming a possible crisis within the system into its development opportunity, requiring high organizational and managerial skills, and the ability to jointly think of the system development scenarios useful to identify the objectives and orient the strategies. Resilience thinking can strengthen those positions that within the spatial planning make up the innovative transformation approaches and, on the other hand, spatial planning can provide proven tools to facilitate the elaboration of development scenarios under of uncertainty. In addition, a resilient process should aim to improve the development of a system even in the absence of disturbances, and this purpose, which I find useful to consider though it is not explicitly stated in the literature on resilience, is well matched with the purposes of territorial planning.

The resilience of a system can be effectively identified by considering three types of complementary performance, that are not always present at the same time in a system (Martin and Sunley 2015). The former is the ability of a system to oppose, or not to suffer, any significant damage to one or more real or potential disorders. The second is the ability of a system to return to an "equivalent" condition to the one before the modification. The third is the ability of a system to seize the opportunities for change, resulting from one or more potentials and/or active disorders to improve itself.

While the first type of performance does not imply any transformation in the system, the other two performances have very different perspectives for a community, which must choose whether to aim to return to an "equivalent" condition to that preceding the system change or try to seize opportunities for change as a result of a disorder. The first choice is often preferred by communities, since they are not obliged to make significant changes to their systems, turning to a "normality" that does not question what this normality entails (Pendall et al. 2010). In addition, when a catastrophic event occurs, this choice is often indirectly and consistently favoured by public and private aid because such aid is geared to compensating for what was before a catastrophic event. Conversely, the second choice is much more complex because it first requires to accept the change and thus to react to a potential disruption by achieving a "leap of quality" into the system. To a community this means identifying and making the most innovative factors necessary for change, while increasing its adaptive ability. The anticipation of change requires action to guide innovative factors on those values of the community that give stability to the system and this can be regenerated with broad consensus on the identity and symbolic references of the community (Portugali 2000). This involves the identification of the system's identity characters, that is, the set of values (perceptive, relational, functional) through which a system manifests its character. 
Resilience thinking seeks to change the assumptions of approaches to the management of environmental resources based on balance, stability and predictability with other prerequisites capable of considering the dynamics of change. Specifically, it makes the most advanced outcomes in the management and governance of territorial systems such as overcoming the paradigm of command and control, taking into account in an integrated way the human and natural factors and, in general, the whole dimension of problems to address and focus on interscale interactions. With regard to the latter, the effects on the different scales of resilient strategies are considered, as what happens in the upper and lower scales affects the resilience of the system considered and, in general, the connections to the different scales, if appropriately oriented, increase the overall resilience of the system. ${ }^{2}$ On the other hand, reductions in the overall resilience of a system may also be the unintended consequence of resilience strategies that do not take into account the effects of feedback and interaction stemming from the changes produced by those strategies at different scales. This can also lead to the need for some subsystems to change in order to maintain a resilient system. For example, in the case of agricultural areas characterized by an increase in drought periods due to climate change, crops with higher water consumption per unit of product could be sacrificed at such times in order to ensure water supply to other agricultural crops.

Resilience thinking has taken as a goals the achievement of a robust and extensive participation in the development of change-oriented strategies and the fostering of spread knowledge and learning in communities and it has considered change and uncertainty as intrinsic factors of systems. These goals have required to adopt and contribute to the development of tools such as comanagement, adaptive management and adaptive comanagement. The first one keeps attention to how users are involved in the decision-making process and it is characterized by the search for a strong operative connection between the community and public executives and officials. The second one adopts as strictly as possible the "learning by doing" criterion to deal with situations of uncertainty (Armitage et al. 2009). The third one is a synthesis of both methods because it is a flexible resource management system that allows to learn from your own actions and change them and it is therefore very useful in governing long-term processes where stakeholders

\footnotetext{
${ }^{2}$ Overall resilience is the resilience that applies to all components of the reference system and the above and below systems affected directly and indirectly by the strategies considered.
}

are self-organizing and share managerial responsibilities with public staffs (Olsson et al. 2004).

The exploration of the relationship between resilience thinking and planning is at the beginnings and can be seen in the two directions of the relation: how resilience thinking can be useful to planning and what planning can do to increase the resilience of a system.

In order to make resilience thinking useful to planning, this concept should be clearly and effectively declined in urban planning, identifying the cognitive tools, the forms of interaction and the operating dimensions (Newman et al. 2009). In particular, resilience thinking can influence planning in three ways: making new metaphors available on the nature of changes in systems that favour renewal and uncertainty, providing new visions and tools for analysing dynamics in urban systems and activating more effective urban and territorial governance modes.

Planning can help to increase the resilience of a system by improving the capacity to govern/manage both predicted emergencies and catastrophes, as well as uncertain change phenomena; the organization of strategies, actions, interventions in the management of disorders in the antecedent, synchronous and subsequent phases; the enhancement of the capacity to seize opportunities by existing and potential crises to innovate the system. In addition, planning can provide the tools for systematic monitoring of strategies and actions and makes the system able to change them in case they deviate from the set objective and learn from the experiences it has made.

\section{Possible integration between urban metabolism and resilience thinking}

Urban metabolism is a concept that focuses on dissipative systems ${ }^{3}$ and considers the city and the territory in an entropic way, concentrating primarily on direct and indirect flows of material, energy and information. ${ }^{4}$ In the resource budgets it has the main references to define the objectives of a plan and to identify the strategies and actions and focuses primarily on urban and territorial structures and infrastructures, where energy, materials

\footnotetext{
${ }^{3}$ Dissipative system (Prigogine 1981) is an open system that works in a state away from the thermodynamic equilibrium by exchanging with the environment energy, material and information.

${ }^{4}$ From an entropic point of view, the information, considered in its multiple aspects of genetic, cognitive, educational, training, organizational and archival type and taking into account the elements through which it flows and accumulates and is used and managed, it is the resource that allows to reduce the use of material and energy resources at the same level of activities, functions and services performed (Rifkin 1980). Information is also the resource that characterizes the dissipative systems, that is, the biosphere, including all living beings, and the anthropic and natural organization, which acquire negentropy from the environment by expelling entropy (Prigogine 1981).
} 
and information are consumed and accumulated and they transit, on the behaviours of inhabitants, communities and companies that influence such flows and on the economic costs of all the activities related to their management.

At the contrary of the concept of resilience, the concept of urban metabolism is rigorously defined and that makes its application in the various fields in which it is used more accurate and shared, planning included. The analysis and evaluation factors that characterize the urban metabolism approach are therefore conceptually identifiable and measurable, and their measurement finds a useful tool in lifecycle analysis.

Resilience is an attitude of a system that in itself is neither "good" nor "bad" and that, if well built and maintained over time, allows a system to remain in the long run without having to overturn its structural characteristics. That is why resilient strategies require to be associated with goals. Many experts tend to incorporate environmental and social sustainability objectives in resilience capacity (Folke 2006; Stockholm Resilience Centre 2009), the achievement of which contributes to maintain the system in a stable state over time. In addition, in order to develop a resilient strategy, the levels of possible trade-offs between the different values (environmental, economic, social, cultural, territorial,...) of a system should be defined and hence there is a need to use tools that identify the thresholds for the proper use of different resources, such as those used in urban metabolism analysis.

Thus, sustainability is the ability of a system to last over time and covers environmental, economic and social performance, with particular attention to possible future scenarios and the development of strategies to achieve the desired scenario. Resilience is the ability of a system to tackle the foreseen and unexpected disturbances over time, developing an adaptation capacity of appropriate magnitude and character to absorb them in a non-traumatic way. Resilience does not require much performance as well as building social and natural capital to deal with future uncertainties (Redman 2014).

To integrate resilience thinking and urban metabolism, the identification of the strategic goals should be based on the concept of urban metabolism. In this regard, the relationship between territories and local and global resource flows, which represent one of the main structural components of the development, is a central aspect of resilience because the territories must be able to intercept such flows and interact by adapting to these dynamics.

The use of resilience thinking in spatial planning integrated with the concepts of urban metabolism improves the quality of solutions developed in the perspective of dynamic environmental sustainability since taking into account these goals, typical of urban metabolism, stimulates and promotes the considerations of aspects such as the adaptation, the ability to act in uncertainty, the balanced and efficient redundancy of resources, infrastructures, and connections, the support to the communities to improve their capacity to provide adequate responses to changes in social, economic, and environmental factors. Through the concept of resilience it is possible to favor the consideration of factors such as social cohesion, with which are indicated the set of behaviors and ties of affinity, trust and solidarity between the individuals of a community, the awareness of the community conditions and of the behavior and action effects of their members, the civic sense, understood as the propensity of a relevant part of a community to contribute to the protection and improvement of the conditions of collective well-being.

On the other hand, through the use of urban metabolic principles, criteria and tools, it is possible to contribute to improve the quality of analyzes and evaluations of many resilience factors that require quantifying available resources and identifying thresholds for possible instability in the system considered. For example, in defining the adaptive strategies of a system under poor availability of resources, in identifying the amount of redundant resources that could be used by a system to provide efficient performance when an element fails or an unpredictable event happens, in favoring the connectivity between subsystems of a system and between the latter and other systems to increase its ability to withstand pressures and to continue to perform the functions previously performed.

\section{The analysis of the Progetto Seveso based on the concepts of resilience and urban metabolism}

In order to better understand what can be the contributions that resilience thinking and urban metabolism can give to territorial planning, on the basis of the evaluation criteria derived from such approaches, an articulated and complex territorial transformation project has been analyzed. This project, called Progetto Seveso, is part of a set of plans and programs developed over time and it is the ultimate outcome of a long process of decades through which the set of indications of hydraulic regimation and landscape-environmental redevelopment affects the stream Seveso.

The Progetto Seveso addresses in an integrated way the management of one of the main flows of urban metabolism, which is the water, it is based on tools that have resilient characters and has activated other resilient bottom-up projects and actions.

The purpose of this analysis is not to evaluate the Progetto Seveso but to indicate how much it can be related to resilience thinking and urban metabolism. Therefore, this 
section considers the planned interventions included not only in the Progetto Seveso, but also the ones in plans, programs and projects that concern the area and directly or indirectly affect the hydraulic regimation and environmental reclamation of the stream Seveso, and constitute the framework for that project.

\section{Objectives and characters of the project}

The Progetto Seveso, drawn up within the framework of the national plan of works and interventions for the reduction of hydrogeological risk, which is called Italia Sicura, was elaborated and approved in 2015 as a result of the highly damaging floods affecting some municipalities, including Milan, along the stream Seveso. The objective is to respond to the ever-increasing need to control those phenomena that have been taking place with increasing intensity in these areas for several decades. This project realizes much of what was planned in sectoral and general plans and programs following the availability of financial resources from the Municipality of Milan, the Lombardy Region and the National Government.

While the main objective is to ensure the safety of the area crossed by the stream, the Progetto Seveso has taken on some complementary objectives of environmental enhancement such as the protection and connection of natural, semi-natural and agricultural areas, the improvement of water quality, the increasing of biodiversity and recreational use of the areas crossed by the stream, the reduction of the vulnerability to the climate change, the enhancing of land-use maintenance. Interventions have started in 2015 and are following a program that plans to complete the hydraulic works in 2020 and the environmental ones in 2025.

The Seveso stream crosses one of the most urbanized areas of Lombardy and Italy (see Fig. 1), and has had a strong urbanization process, especially developed after the Second World War, which has led to a significant increase in the speed of meteoric water flow, a drastic reduction of golem surfaces and the worsening of water quality. The intervention area concerns the stream Seveso and other nearby streams, including the floodable areas and those ones subject to interventions of hydraulic regimation and landscape-environmental regeneration.

The Progetto Seveso assumes the Po River Basin Authority's approach to minimize the risk of flooding and foresees the rolling and checking of floods in the waterway, avoiding diversion into other water courses. This is because there is a general fragility of the waterline of the territory that goes from the river Ticino to the river Adda and therefore there is no intention to increase the amount of water of the stream Seveso, which is of low quality, discharged into the river Ticino through the northwest canal (NOC).

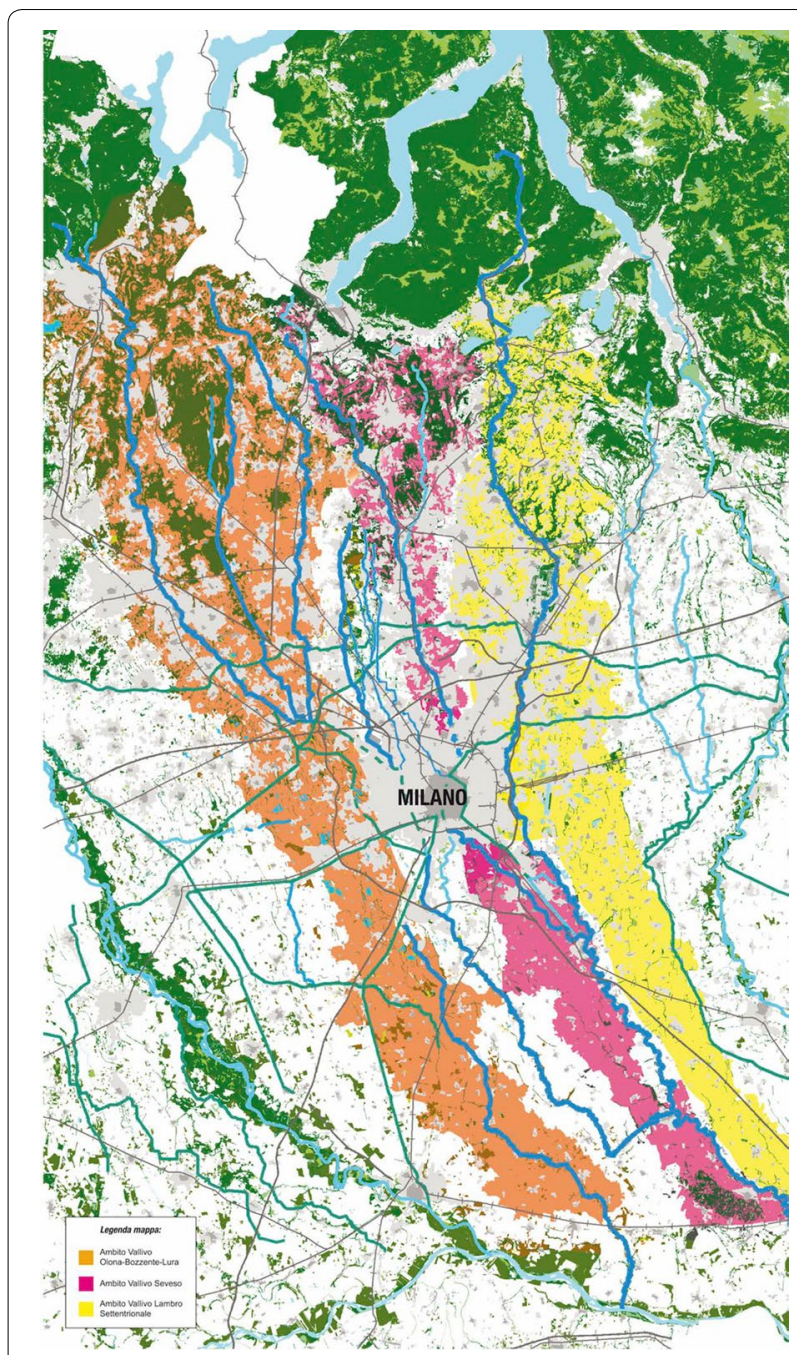

Fig. 1 Territorial framing of the stream Seveso river basin (Source: Contratto di fiume del Seveso)

The main projects of the Progetto Seveso are:

1. building of rolling tanks and flooding areas in the Seveso's floodplains.

2. doubling of the NOC flow from 30 to $60 \mathrm{~m}^{3} / \mathrm{s}$, as the canal is a fundamental work for the defense of the city of Milan, so as to complete the doubling already built.

3. restoring the functionality of river crossings in the subsoil of Milan and the removal of sediments in the covered area.

4. the closure of the small purification plant of Varedo and the transfer of its waters into the much larger purification plant of Pero and the completion of sewerage in the 12 municipalities that drain their wastewater directly into the stream Seveso. 
5. the implementation of extensive environmental redevelopment projects, including the renaturalisation of the banks of the stream Seveso and the area of the purification plant of Varedo once it will be dismantled, the works of phytodepuration and drainage of water in some urban areas, the environmental redevelopment of the areas affected by the rolling tanks.

6. the extraordinary maintenance intervention of the riverbed and shores of Seveso after flood waves.

\section{The analysis of the Progetto Seveso from the point of view of urban metabolism}

In the Progetto Seveso there are several principles that refer to the concept of urban metabolism since water and natural and economic resources are considered in an integrated way and the information and knowledge about these resources are used to identify more effective interventions from both constructive and management point of views.

Economic resources have been found when were identified the actions to be taken to meet the goals of containing throughout the stream the 100-year return floodplains, to improve the landscape and the environment and to obtain social consensus to the interventions to be carried out. Thus, through a comparison between the cost estimate for the interventions and the available economic resources, the three institutions that finance the Progetto agreed on the economic contribution of each one to achieve the objectives set (i.e., the City of Milan for about 45 million euro, the Lombardy Region for about 35 million euros and the Italian government for about 100 million euros).

Water resources have been considered both quantitatively and qualitatively, as measures include the mitigation of hydraulic risk, the improving of water quality, the river retraining and a sustainable management of urban drainage. From the quantitative point of view, the historical series of seasonal water dynamics of all the areas that the stream Seveso crosses are considered, while from the qualitative point of view the historical series on the quality of surface and underground waters have been considered.

The consideration of the quantitative aspects was used to define an integrated rolling tanks system of flood waves distributed in the river basin, while the integrated consideration of the quantitative and qualitative aspects has characterized the structural aspects of the solutions. That is because it was decided not to discharge in the river Ticino the Seveso waters, being the Ticino water of a much higher quality, to complete the sewage collection throughout the stream Seveso and to optimize the water purification system to greatly improve the quality of the water that will end up in the rolling tanks. Finally, special arrangements have been made in the management of rolling waters and the maintenance of the relative tanks including the control of the interference with the aquifers and the periodic removal of the residues and sediments.

The Progetto Seveso has also adopted a systemic approach to the design of interventions of environmental redevelopment in some areas crossed by the stream. Seveso was considered a "green infrastructure" in which are carried out interventions of de-fragmentation of landscape and ecosystems and biodiversity increasing, through the construction of shrub zones and tree bands and the naturalization of slopes, of usability enhancing, through the construction of spaces and paths for playing, exhibition and didactic related to water, and interventions of connection, by building cycle-pedestrian pathways and integrating them with existing paths in the crossed green areas.

The seven rolling tanks are located close to the urbanized areas and allow to handle high volumes of water. Their design has considered the requirements of hydraulic and environmental safety, the environmental and landscape integration and the relationship with local communities. All rolling tanks will be held clean and without materials and wastes and will be subjected to periodic cutting of lawns. The excavations for the construction of rolling tanks and ancillary works require the movement of large quantities of land for which a balance has been made between the land to be reused in the arrangement of slopes, embankments, artifacts and landscaping items and the land to be disposed in landfills.

\section{The analysis of the Progetto Seveso from the point of view of resilience thinking}

Among the numerous analytical and design factors that characterize resilience thinking, for the analysis of the Progetto Seveso has been considered the ones that are most widely used in literature, such as adaptability, robustness, redundancy, diversity, connectivity, social cohesion, information and participation.

The Progetto is part of the Seveso River Agreement, which was signed in 2006 by the River Po Basin Authority, the Interregional Po Agency, and all local authorities concerned, and it is based on many general (see, for example, the regional and provincial spatial plans) and sectorial (see, for example, the water protection plan, the flood risk management plan, the rural development programs, the plans of management of protected areas) planning tools developed over two decades which are characterized by a good integration.

From a participatory point of view, the Progetto Seveso has involved the interest of many stakeholders, such as the population and the activity managers located in the alluvial areas, the inhabitants of the areas affected by lamination tanks or by landscaping-environmental 
redevelopment, and has the contribute of all the institutional levels with expertise in the area (Region, Provinces, Basin Authorities, Municipalities). Participation was done on the basis of the process of the Environmental Impact Assessment of the Progetto Seveso, but it has also been developed in the design of the Plan of Sub-Basin and the definition of river retraining interventions. There also have been many bottom-up initiatives to discuss on the functional, constructive and managerial features of rolling tanks along with the dissemination of information and cultural activities on water. Finally, various institutional and not institutional initiatives were initiated involving the population to better tailor interventions to local interests. ${ }^{5}$

The Progetto does not increase so much the capacity of the system to adapt to the water dynamics, which is already quite high since the whole area has been subjected to alluvial episodes for several decades and has therefore built good adaptation mechanisms over time, as well as its capacity to oppose structurally and organizationally to such events. By this Progetto it is possible to achieve a good integration between adaptability and robustness, integration that is a fundamental objective for the resilience of a system. However, it will still be necessary to maintain that degree of awareness and organization already existing in the community so that it is not unprepared in case of extreme events exceeding the centenary flood waves.

Redundancy has been considered for hydraulic aspects in terms of modularity and connectivity, which is the most efficient way to manage unforeseen situations through an increase of a system's elements. Regarding the connections, the Progetto has taken them into account in a systematic and diffused manner from a hydraulic, environmental (ecological networks) and territorial point of views, linking the subsystems and the different dimensions of the system as much as possible.

From a hydraulic point of view, within a project mainly characterized by the regulation of water flows, different types of intervention were carried out including the controlled diversion of water to other watercourses, the cleaning of the riverbeds and the reinforcement of the net of water monitoring to reduce reaction times to alluvial phenomena. Biodiversity has also been enhanced in environmental redevelopment interventions, envisaging the planting of different native plant species.

\footnotetext{
${ }^{5}$ See, for example, the project called "The River Calls", which aims to reduce the community vulnerabilities with regard to hydraulic risk and to improve the capacity of the community to respond to floods and flood waves, through a close collaboration between institutions and communities and the strengthening of existing relationships and competencies.
}

Even through information provided by professionals, local communities have gained a good understanding of what is happening in their territory and the effects that their behaviors may have. This condition has favored the organization of many initiatives of public assessment of the solutions adopted to improve the quality of interventions and their relationship with the environment and communities. This allows to maintain the level of social cohesion despite the Progetto has important trade-off between the different areas of the Seveso basin. In fact, there are disadvantaged areas, such as those not affected by alluvial phenomena where rolling tanks are built, areas with balanced conditions, such as areas affected by alluvial phenomena or improvements in wastewater management where rolling tanks are built, and advantageous areas, such as those affected in the past by alluvial phenomena, by improvements in waste water management or landscaping-environmental improvements without the construction of rolling tanks.

\section{Conclusion}

The integration of resilience thinking with the principles of urban metabolism improves the quality and effectiveness of environmental, social and economic sustainability strategies and actions by operating on all the phases that characterize a planning process such as processing, implementation and management.

Through resilience thinking, the concepts and tools more oriented to the management of complex systems under uncertainty and to the elaboration of solutions where stakeholders are most involved and the bottomup activities and actions which are mostly considered are widespread. Through the concept of urban metabolism, the concepts and tools most geared to the integrated and sustainable management of the resources affecting a territorial system are widespread. Both of these concepts have achieved many innovative aspects of planning, such as the systemic vision, the detection of integrated solutions, the involvement of stakeholders and community and the integration of the processing, implementation and management phases of strategies and actions. Therefore, they can be easily integrated. On the other hand, plans, programs and strategic projects of an advanced character are already explicitly or implicitly inspired by most of the principles and criteria of these two concepts, so we fully or partially find these criteria and concepts in all the most advanced planning experiences.

\footnotetext{
Acknowledgements

Rachele Radaelli has supported me in finding and collecting information about the Progetto Seveso.
}

Competing interests

The author declares that he has no competing interests. 


\section{Availability of data and materials}

The data are available upon request to the author.

\section{Consent for publication}

Not applicable.

Ethics approval and consent to participate

Not applicable.

\section{Funding}

Not applicable.

\section{Publisher's Note}

Springer Nature remains neutral with regard to jurisdictional claims in published maps and institutional affiliations.

Received: 10 November 2017 Accepted: 8 December 2017

Published online: 22 December 2017

\section{References}

Armitage R et al (2009) Adaptive co-management for social-ecological complexity. Front Ecol Environ 7(2):95-102

Carpenter SR, Westley F, Turner G (2005) Surrogates for resilience of socialecological systems. Ecosystems 8(8):941-944
Folke C (2006) Resilience: the emergence of a perspective for social-ecological systems analyses. Glob Environ Change 16(3):253-267

Glaser M, Krause G, Ratter BM, Welp M (2008) Human/nature interaction in the anthropocene: potential of social-ecological systems analysis. GaiaEcological Perspectives for Science and Society, Oekom Verlag, pp 77-80 Gotts NM (2007) Resilience, panarchy, and world-systems analysis. Ecol Soc 12(1):24

Martin R, Sunley P (2015) On the notion of regional economic resilience: conceptualization and explanation. J Econ Geogr 15:1-42

Newman P, Beatley T, Boyer H (2009) Resilient cities: responding to peak oil and climate change. Island Press, Washington, DC

Olsson P, Folke C, Hahn T, 2004, Social-ecological transformation for ecosystem management: the development of adaptive co-management of a wetland landscape in southern Sweden. Ecol Soci. http://www.ecologyandsociety.org/vol9/iss4/art2

Pendall R, Foster KA, Cowell M (2010) Resilience and regions: building understanding of the metaphor. Camb J Reg Econ Soc 3(1):71-84

Portugali I (2000) Self-organization and the city. Springer, Berlin

Prigogine I (1981) La nuova alleanza. Metamorfosi della scienza. Einaudi, Torino Redman CL (2014) Should sustainability and resilience be combined or remain distinct pursuits? Ecol Soc 19(2):37. https://doi.org/10.5751/ ES-06390-190237

Rifkin J (1980) Entropy: A New World View. Viking Press, New York Stockholm Resilience Centre (2009) Resilience and sustainable development 2.0. Report

\section{Submit your manuscript to a SpringerOpen ${ }^{\circ}$ journal and benefit from:}

- Convenient online submission

- Rigorous peer review

- Open access: articles freely available online

- High visibility within the field

- Retaining the copyright to your article

Submit your next manuscript at $>$ springeropen.com 